\title{
A SOURSOP PULP EXTRACTION PROCEDURE
}

Soursop (Annona muricata, L.) is a seasonal, large, oblong fruit in great demand among local processors throughout the year in Puerto Rico. The pulp has a distinctive and highly pleasing flavor and aroma, thus widely used in preparing beverages, sherbets, ice creams and syrups.

No information appears to be available on the extraction and preservation of undiluted soursop pulp. Sánchez et al. ${ }^{1}$ reported a method for extraction of the pulp by dispersing the peeled fruit in water by means of a mechanical agitator, then screening the diluted fruit mixture through a paddle pulper using a 0.033 - or 0.045 -inch screen. Franco et al. ${ }^{2}$ describe a method for extraction by dispersing the peeled fruit in a sugar syrup, then treating the pulp in a horizontal-type pulper equipped with metal paddles.

This study was conducted for the purpose of developing a procedure for extracting and preserving undiluted soursop pulp. Such information will be helpful in achieving greater utilization of this seasonal fruit, also providing a method necessary for packing the material for remanufacturing products throughout the year.

Fully developed soursop fruits were purchased at Salinas, Puerto Ricc and ripened at room temperature without further treatment. A representative sample of the ripe fruit was taken to determine percentage of pulp, peel, core, seeds, and fiber.

Ripe fruit was selected from a wide-mesh conveyor and washed in a soak and spray washer. Soursop can not be peeled satisfactorily by ordinary mechanical means due to the softness of the fruit when ripe. Attempts to remove the peel by the lye-peeling method failed, as a reddish brown discoloration developed which impairs pulp quality. Therefore, hand-peeled fruit was used to obtain high-quality soursop pulp. The fruit was handpeeled and cored; then conveyed to a Langsenkamp E.Z. Adjust Pulper ${ }^{3}$, equipped with two nylon brushes operating at 651 r.p.m. and a 0.060 -inch screen, to separate pulp from seeds and fibers. The pulp was pasteurized in a Votator-type pasteui izer at $185^{\circ} \mathrm{F}$., then packed into No. 10 tin cans and stored at $85^{\circ} \mathrm{F}$.

Pulper performance and efficiency were determined by comparing the

1 Sánchez-Nieva, F., Igaravidez, I., and López Ramos, B., The preparation of soursop nectar, Agr. Exp. Sta. Univ. P.R., Tech. Paper 11, 1953.

${ }^{2}$ Franco-Betancourt, J. J. and Alvarez-Reguera, J., Jugo de frutas cubanas, Instituto Cubano de Investigaciones Tecnológicas, Serie de Estudios sobre Trabajos de Investignción, No. 11, 1960.

3 Trade names are used in this paper solely for the purpose of providing specific information. Mention of a trade name does note constitute a guarantee or warranty of the equipment by the Agricultural Experiment Station of the University of Puerto Rico or an endorsement over other equipment not mentioned. 
percent of pulp extracted in the pulping runs with the percent of available pulp in the raw fruit.

Keeping quality of the canned pulps was determined by processing them into nectars and submitting them to a sensory evaluation panel consisting of 10 to 13 members. The panelists scored the samples according to a 9-point hedonic scale 4 in which 9 stands for "like extremely" and 1 for "dislike extremely".

Representative ripe-fruit samples showed that soursop averages 61.6 percent pulp, 17.0 percent seed and fiber and 21.4 percent peel and core by weight. Table 1 shows the percent of pulp extracted of the available pulp in the fruit and permits a determination of the pulper performance and

TABLE 1.-Soursop pulp yields using a 0.060-inch screen

\begin{tabular}{rcccc}
\hline Run & Fruit & Pulp extracted & $\begin{array}{c}\text { Pulp extracted/ } \\
\text { fruit } \times 100\end{array}$ & $\begin{array}{c}\text { Pulp extracted/ } \\
\text { available pulp in } \\
\text { fruit } \times 100^{1}\end{array}$ \\
\hline & Ponnds & Posnds & Percest & Percent \\
2 & 201.7 & 106.0 & 52.6 & 85.4 \\
3 & 201.0 & 112.7 & 56.1 & 91.1 \\
4 & 201.3 & 110.2 & 54.7 & 88.8 \\
5 & 200.8 & 111.0 & 55.3 & 89.8 \\
6 & 201.0 & 107.5 & 53.5 & 86.9 \\
7 & 150.0 & 87.8 & 58.5 & 94.9 \\
8 & 150.0 & 91.8 & 61.2 & 99.4 \\
9 & 150.0 & 92.3 & 61.4 & 99.7 \\
10 & 150.0 & 89.5 & 59.7 & 96.9 \\
\hline Average & 150.0 & 89.5 & 59.7 & 96.9 \\
\hline
\end{tabular}

1 Available pulp in the fruit $=61.6$ percent.

efficiency in extracting soursop pulp under the conditions of the test. The performance calculated in this way averaged 93.0 percent as shown in table 1. A very good pulp extraction was obtained using an E. Z. Adjust Pulper operating at 651 r.p.m. and equipped with a 0.060 -inch screen.

The sensory evaluation of the nectars prepared from the canned soursop pulps rated them as of good quality throughout the period of storage. It can be concluded therefore that the pulps did not undergo appreciable change during a storage period up to 360 days at $85^{\circ} \mathrm{F}$., and that good soursop nectars can be prepared from such pulps.

José $R$. Benero
Angel $J$. Rodríguez
A wilda Roman de Sandoval
Food Technology Laboratory

4 Peryam, D. R. and Pilgrim, F. J., Hedonic scale method of measuring food preferences, Food Technol. 11 (9): 9-14, 1957. 